\title{
Successful Outcomes with Insulin Degludec in Pregnancy: A Case Series
}

Siwaporn Hiranput · S. Haris Ahmed · Deborah Macaulay •

Shazli Azmi

Received: October 1, 2018 / Published online: November 15, 2018

(C) The Author(s) 2018

\section{ABSTRACT}

Optimal glycaemic control pre-conception and throughout pregnancy is paramount to achieve the best outcomes and to minimise the risk of complications for the mother and baby. Current long-acting insulin analogues that have been approved by the National Institute for Health and Care Excellence in the UK for use in pregnancy include glargine and detemir. In many patients, these treatments have limitations because of their pharmacokinetic properties thus not enabling optimal glycaemic control. Efforts at rapidly achieving the recommended blood glucose targets with these analogues can be associated with recurrent and/or disabling hypoglycaemia. Degludec is a second-generation ultra-long-acting insulin analogue, which has been shown to mimic endogenous basal insulin production by the pancreas. This may offer patients better control with less hypoglycaemia

Enhanced Digital Features To view enhanced digital features for this article go to https://doi.org/10.6084/ m9.figshare.7285364.

S. Hiranput · S. H. Ahmed ( $₫) \cdot$ D. Macaulay Department of Endocrinology and Metabolic Medicine, Countess of Chester Hospital NHS Foundation Trust, Chester, UK e-mail: asyedharis76@gmail.com

S. Azmi

Manchester Diabetes Centre, Manchester University Foundation Trust, Manchester, UK where first-generation insulins fail. There are currently no randomised controlled studies to support the use of insulin degludec in pregnancy. We report three cases of women who were on insulin degludec during pregnancy and achieved successful outcomes. Two of them were commenced on this during pregnancy because of hypoglycaemia with licenced insulin therapy. All the women showed an improvement in glycaemic control during pregnancy. There was attenuation of a wide glycaemic variability as demonstrated by a continuous glucose monitoring (CGM) system in one of the patients. They all delivered healthy babies. This case series highlights the urgent need for large randomised control trials to establish the safety and efficacy of insulin degludec in pregnancy.

Keywords: Insulin degludec; Pregnancy; Type 1 diabetes; Type 2 diabetes

\section{INTRODUCTION}

Optimal glycaemic control before and throughout pregnancy plays an important role in minimising detrimental effects on the foetus, pregnant women, and neonates. Insulin remains the gold standard of treatment for achieving blood glucose targets during pregnancy in patients with type 1 diabetes mellitus and in those with type 2 or gestational diabetes mellitus 
where metformin monotherapy is not tolerated or unlikely to achieve glycaemic targets [1].

Insulin analogues, such as rapid-acting lispro and aspart, and long-acting (or basal) glargine and detemir are licensed and have been approved by the National Institute for Health and Care Excellence (NICE) for use in diabetes during pregnancy in the UK [1]. The basal insulins analogues have been, in theory, designed to mimic the secretion of endogenous basal insulin. Whilst they have demonstrated good glycaemic control in pregnant women, they have limitations due to their pharmacokinetic profiles. Their activity rises to a peak/plateau gradually and then declines, thereby producing peaks and troughs that can potentially cause hypo- and hyperglycaemia. Degludec is a newer ultra-long-acting basal insulin analogue that has shown a prolonged duration of action ( $>42 \mathrm{~h}$ ) and the absence of peak in plasma concentration/activity in nonpregnant subjects $[2,3]$. It reaches a steady-state concentration with 3 days of administration. A half-life of $>25 \mathrm{~h}$ ensures lower intra-subject variability within a $24-\mathrm{h}$ dosing interval. This would provide a potential advantage for its use in pregnancy to achieve glycaemic goals without the increased risk of maternal hypoglycaemia. However, there is no evidence from controlled studies about the long-term safety and efficacy to support the use of insulin degludec in pregnancy.

We report three cases of women with preexisting diabetes under our joint diabetes and antenatal clinic at a district general hospital who successfully conceived on therapy with degludec during pregnancy. The women had made an informed choice to be continued (case 1) or commenced (cases 2 and 3) on insulin degludec as a therapeutic trial to help them achieve their glycaemic goals in pregnancy. Informed consent was obtained from all individual participants for being included in the case series.

\section{CASE 1}

A 36-year-old female with type 2 diabetes for 6 years was commenced on degludec prior to conception because of previous intolerance to insulin isophane, detemir, and glargine. Her

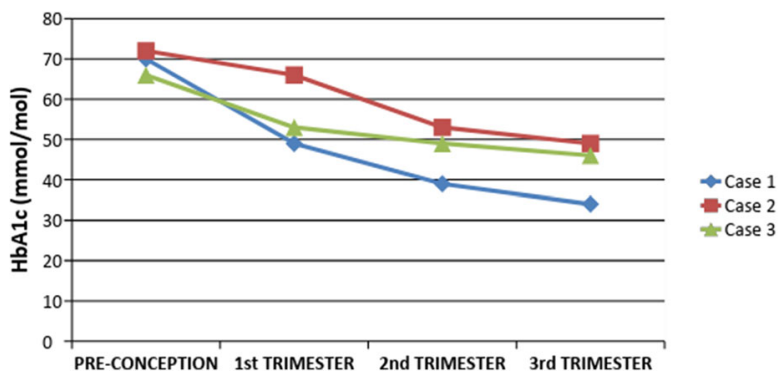

Fig. 1 Glycaemic control pre-conception and during pregnancy

median daily glycaemia at the first visit was $7.9 \mathrm{mmol} / \mathrm{l}(5.8-8.5 \mathrm{mmol} / \mathrm{l})$; this was reduced to $5.6 \mathrm{mmol} / \mathrm{l}(4.3-6.8 \mathrm{mmol} / \mathrm{l})$ at delivery. Pre-conception body mass index was $35 \mathrm{~kg} / \mathrm{m}^{2}$, and glycated haemoglobin (HbA1c) was $70 \mathrm{mmol} / \mathrm{mol}$ (8.6\%). HbA1c decreased to $49 \mathrm{mmol} / \mathrm{mol}(6.6 \%)$, $39 \mathrm{mmol} / \mathrm{mol}(5.7 \%)$, and $34 \mathrm{mmol} / \mathrm{mol}(5.3 \%)$ during the first, second, and third trimester, respectively (Fig. 1). The degludec dose at delivery was $2.5 \mathrm{IU} / \mathrm{kg} /$ day of the double strength (U200). She had gained $15 \mathrm{~kg}$ during the pregnancy.

She delivered by elective caesarean section at 38 weeks of gestation. The baby was $3850 \mathrm{~g}$ in weight. The APGAR (Appearance, Pulse, Grimace, Activity, and Respiration) score was 9 and 9 at 1 and $5 \mathrm{~min}$, respectively. There were no perinatal complications and the baby did not require neonatal intensive care unit admission (Table 1). The mother is regularly seen in the diabetes clinic and reports a healthy 3 year old achieving normal milestones.

\section{CASE 2}

A 23-year-old female with a 16-year history of type 1 diabetes and no micro- or macro-vascular complications was changed from glargine to degludec at 8 weeks into her pregnancy due to severe hypoglycaemia with significant glycaemic variability (Fig. 2). She had previously declined insulin pump therapy. Her median daily glycaemia at the first visit was $9.8 \mathrm{mmol} / \mathrm{l}(2.2-$ $12.3 \mathrm{mmol} / \mathrm{l})$; this was reduced to $5.7 \mathrm{mmol} / \mathrm{l}$ (4.8-8.1 mmol/l) at delivery. Pre-conception body mass index was $22 \mathrm{~kg} / \mathrm{m}^{2}$, and HbA1c was $72 \mathrm{mmol} / \mathrm{mol}$ (8.7\%). HbA1c decreased to $66 \mathrm{mmol} / \mathrm{mol}(8.2 \%), 53 \mathrm{mmol} / \mathrm{mol}(7.0 \%)$, and 
Table 1 Demographic summary of the patients, maternal and neonatal outcomes

\begin{tabular}{|c|c|c|c|}
\hline & Case 1 & Case 2 & Case 3 \\
\hline Age (years) & 36 & 23 & 34 \\
\hline Diabetes duration (years) & 6 & 16 & 22 \\
\hline Pre-pregnancy BMI $\left(\mathrm{kg} / \mathrm{m}^{2}\right)$ & 35 & 22 & 23 \\
\hline $\begin{array}{l}\text { New onset or progression of pre-existing } \\
\text { microvascular disease during pregnancy }\end{array}$ & No & No & No \\
\hline \multicolumn{4}{|l|}{ Degludec treatment during pregnancy } \\
\hline Indication & $\begin{array}{l}\text { Intolerance to isophane, } \\
\text { detemir, and glargine } \\
\text { insulins }\end{array}$ & $\begin{array}{l}\text { Severe hypoglycaemia; } \\
\text { declined insulin pump } \\
\text { therapy }\end{array}$ & $\begin{array}{l}\text { Recurrent } \\
\text { hypoglycaemia }\end{array}$ \\
\hline Weeks & $0-38$ & $8-38$ & $12-38$ \\
\hline Dose at delivery (IU/kg/day) & 2.5 & 0.25 & 0.18 \\
\hline Strength of formulation & U200 & U100 & U100 \\
\hline \multicolumn{4}{|l|}{$\mathrm{HbAlc}(\mathrm{mmol} / \mathrm{mol})$} \\
\hline Pre-conception & 70 & 72 & 66 \\
\hline First trimester & 49 & 66 & 53 \\
\hline Second trimester & 39 & 53 & 49 \\
\hline Third trimester & 34 & 49 & 46 \\
\hline \multicolumn{4}{|l|}{ Median daily glycaemia $(\mathrm{mmol} / \mathrm{l})^{\mathrm{a}}$} \\
\hline At first visit & $7.9(5.8-8.5)$ & $9.8(2.2-12.3)$ & $7.4(2.4-10.2)$ \\
\hline At delivery & $5.6(4.3-6.8)$ & $5.7(4.8-8.1)$ & $5.8(4.0-8.2)$ \\
\hline Weight gain at the end of pregnancy $(\mathrm{kg})$ & 15 & 9 & 8.2 \\
\hline Time of delivery (gestational weeks) & 38 & 38 & 38 \\
\hline Delivery & Elective caesarean & Forceps delivery & $\begin{array}{l}\text { Elective } \\
\text { caesarean }\end{array}$ \\
\hline \multicolumn{4}{|l|}{ New-born } \\
\hline Birthweight (g) & 3850 & 3680 & 3660 \\
\hline Congenital malformations & No & No & No \\
\hline APGAR score (at 1 and $5 \mathrm{~min}$ ) & 9 and 9 & 9 and 10 & 9 and 9 \\
\hline Neonatal hypoglycaemia & No & No & No \\
\hline NICU admission & No & No & No \\
\hline
\end{tabular}

${ }^{a}$ Average of the daily median capillary glucose values, taken over 7 consecutive days prior to day of visit

$49 \mathrm{mmol} / \mathrm{mol}(6.6 \%)$ during the first, second, and third trimester, respectively (Fig. 1). Glycaemic variability improved significantly on degludec (Fig. 3). The degludec dose at delivery was $0.25 \mathrm{IU} / \mathrm{kg} /$ day of the standard strength (U100). Her gestational weight gain was $9 \mathrm{~kg}$. 


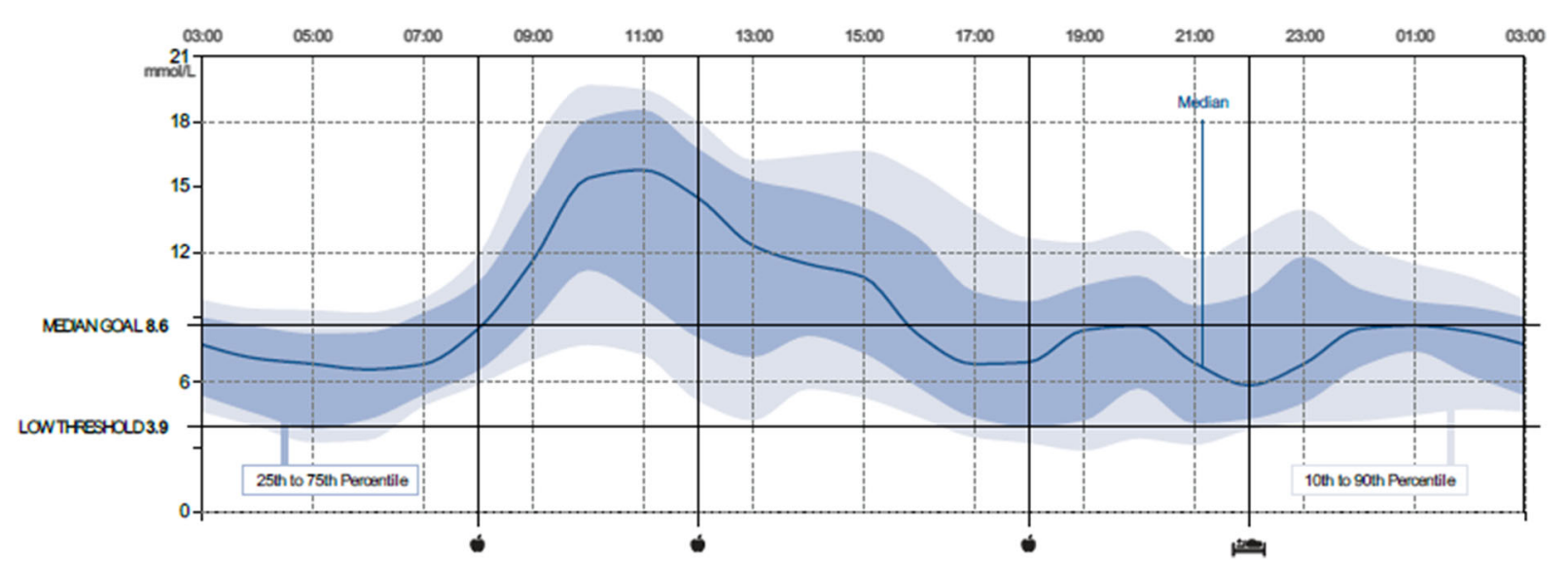

Fig. 2 CGM profile in patient 2 obtained by FreeStyle Libre ${ }^{\circledR}$ prior to degludec treatment

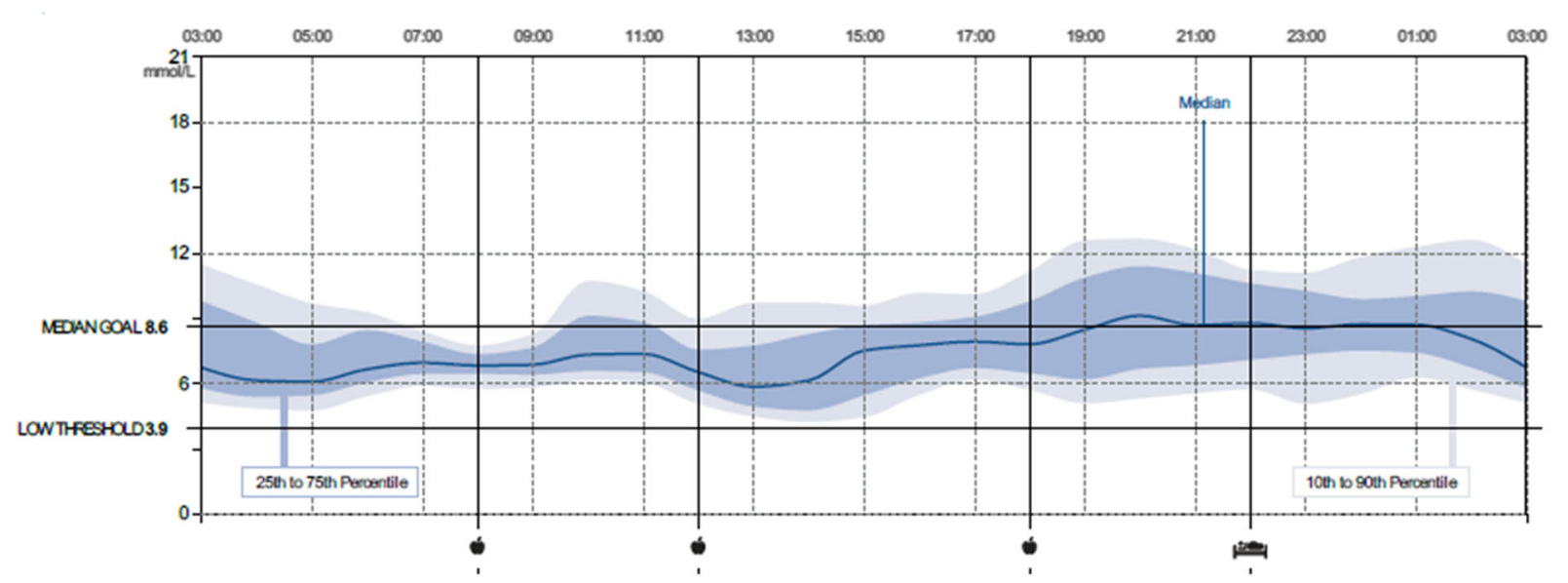

Fig. 3 CGM profile in patient 2 obtained by FreeStyle Libre ${ }^{\circledR}$ during degludec treatment

The course of pregnancy was uneventful. Labour was induced at 38 weeks of gestation with assisted delivery using forceps. The baby was $3680 \mathrm{~g}$ in weight. The APGAR score was 9 and 10 at 1 and $5 \mathrm{~min}$, respectively (Table 1).

\section{CASE 3}

A 34-year-old female diagnosed with type 1 diabetes since the age of 13 . She had previous laser treatment for proliferative diabetic retinopathy that was quiescent for last 7 years. The patient was on novorapid and detemir until 12 weeks into her pregnancy when her basal insulin was switched to degludec because of recurrent hypoglycaemia. Pre-conception body mass index was $21 \mathrm{~kg} / \mathrm{m}^{2}$, and $\mathrm{HbA1c}$ was $66 \mathrm{mmol} / \mathrm{mol}$ (8.2\%). HbA1c decreased to $53 \mathrm{mmol} / \mathrm{mol}$ (7.0\%), $49 \mathrm{mmol} / \mathrm{mol}(6.6 \%)$, and $46 \mathrm{mmol} / \mathrm{mol}(6.4 \%)$ during the first, second, and third trimester, respectively (Fig. 1). The degludec dose at delivery was $0.18 \mathrm{IU} / \mathrm{kg} /$ day of the standard strength (U100). She had gained $8.2 \mathrm{~kg}$ during her pregnancy. She had retinopathy screening every trimester and no new microvascular event was noted.

She delivered a healthy baby at 38 weeks of gestation by an elective caesarean section. The 
baby was $3660 \mathrm{~g}$ in weight and the new-born assessment was unremarkable (Table 1).

\section{DISCUSSION}

Poor glycaemic control causes significant risk to the mother in addition to increased foetal morbidity and mortality due to increased rates of miscarriage, preterm labour, congenital malformations, macrosomia, and neonatal hypoglycaemia. These complications could be prevented by promoting tight glycaemic control. This is however difficult to achieve without the associated risk of hypoglycaemia.

The safety and efficacy of the insulin analogue in pregnant women were first reported in 1999 with lispro [4]. This has led to larger-scale clinical trials that confirmed its beneficial effects in rapidly lowering the postprandial glucose levels during pregnancy without causing additional harm to the foetus $[5,6]$. Longacting insulin analogues are required along with short-acting insulin analogues to manage glycaemia through the day. Long-acting insulin analogues currently approved by Food and Drug Administration (FDA) for use in pregnancy are glargine and detemir. Insulin glargine is associated with within-subject variability and high affinity for insulin-like growth factor 1 (IGF-1) receptor, leading to unexpected hypoglycaemia and concerns regarding mitogenic potential, respectively $[7,8]$. Insulin detemir, although it demonstrates low variability, is dose-dependent and appears to have a shorter duration of action at lower doses and may require twice daily dosage in those with higher basal insulin requirement [8].

Although insulins glargine and detemir are proven to be safe in pregnancy and non-inferior in their efficacy compared with human insulin, they do not meet the criterion of an ideal basal insulin that would, in theory, have a duration of action long enough to reduce intra-patient and inter-dose variations in insulin concentration in the steady state. Degludec is the newgeneration long-acting insulin analogue that comes close to addressing this criterion. It is manufactured through modification of human insulin whereby the threonine at position B30 is deleted and a 16-carbon fatty diacid is added to lysine at position B29 via a glutamic acid spacer [8]. These structural changes allow soluble multi-hexamers to form upon subcutaneous injection and for continuous slow release of degludec monomers, without variation in the concentration once a steady state has been reached. With a once daily injection, degludec provides a uniform glucose-lowering effect with the duration of action that extends beyond $24 \mathrm{~h}$. This unique pharmacokinetic property lowers the risk of nocturnal hypoglycaemia that has been supported by many studies [9-11]. Furthermore, it demonstrates low IGF-1 receptor binding affinity and low mitogenic potential [8].

Published reports on two cases of females with type 1 diabetes who were on degludec prior to conception have described no longterm adverse effects after it was promptly discontinued in the first trimester upon confirmation of pregnancies [12]. A more recent case report described a successful pregnant outcome in a woman with type 2 diabetes who was on degludec pre-conception and had continued the treatment throughout pregnancy [13]. To date, there are no results of randomised clinical trials of degludec use during pregnancy, given the ethical concern of potential harm to the foetus, although animal reproduction studies have not revealed any difference between insulin degludec and human insulin regarding embryotoxicity and teratogenicity [14].

The fear of foetopathy and adverse pregnancy outcomes per se elicits positive maternal behaviour and attitudinal changes in most pregnancies leading to modest-to-significant improvement in glycaemic control. Healthcareenabled factors such as use of CGM [15], regular specialist contacts, easier access to specialist advice, and capillary blood glucose (CBG) monitoring equipment contribute to the improvement [16]. But the single most important contributor that dictates the hard-end point of a successful pregnancy outcome is the patient's glycaemic journey within the clinically defined euglycemic parameters, which can be facilitated by the pharmacological treatment provided. 
In these three patients who failed or did not tolerate treatment with the insulins glargine or detemir, insulin degludec demonstrated a marked improvement in glycaemic control as demonstrated by the trends in HbA1c (Fig. 1) and lower glycaemic variability, without causing any diabetes-related or foetal/maternal complications. The pregnant state did not appear to affect the pharmacodynamics or pharmacokinetics of insulin degludec. Cases 1 and 3 elected to have a caesarean section. Case 2 was delivered by forceps for the obstetric indication of prolonged labour in a nulliparous woman. There were no adverse neonatal outcomes.

Our cases highlight insulin degludec as a potential alternative to existing basal insulin analogues licensed for use during pregnancy. This is especially pertinent to those patients who have recurrent or severe hypoglycaemia despite intensive management with currently licensed analogues who would otherwise progress to insulin pump therapy. Larger controlled clinical trials are warranted to establish the safety and efficacy profile of degludec in pregnancy.

\section{ACKNOWLEDGEMENTS}

We thank the participants of this case series.

Funding. No funding or sponsorship was received for this study or publication of this article.

Authorship. All named authors meet the International Committee of Medical Journal Editors (ICMJE) criteria for authorship for this article, take responsibility for the integrity of the work as a whole, and have given their approval for this version to be published.

Disclosures. The authors (Siwaporn Hiranput, S. Haris Ahmed, Deborah Macaulay and Shazli Azmi) have nothing to disclose.

Compliance with Ethics Guidelines. Informed consent was obtained from all individual participants for being included in the case series.

Data Availability. Data sharing is not applicable to this article as no data sets were generated or analyzed during the current study.

Open Access. This article is distributed under the terms of the Creative Commons Attribution-NonCommercial 4.0 International License (http://creativecommons.org/licenses/ by-nc/4.0/), which permits any noncommercial use, distribution, and reproduction in any medium, provided you give appropriate credit to the original author(s) and the source, provide a link to the Creative Commons license, and indicate if changes were made.

\section{REFERENCES}

1. NICE. Diabetes in pregnancy: management of diabetes and its complications from preconception to the postnatal period. http://www.nice.org.uk/ guidance/ng3. Accessed 22 Jun 2018.

2. Kalra S. Insulin degludec: a significant advancement in ultralong-acting Basal insulin. Diabetes Ther. 2013;4(2):167-73.

3. Heise T, Nosek L, Bøttcher SG, et al. Ultra-longacting insulin degludec has a flat and stable glucose-lowering effect in type 2 diabetes. Diabetes Obes Metab. 2012;14(10):944-50.

4. Jovanovic L, Ilic S, Pettitt DJ. Metabolic and immunologic effects of insulin lispro in gestational diabetes. Diabetes Care. 1999;22(9):1422-7.

5. Bhattacharyya A, Brown S, Hughes S, et al. Insulin lispro and regular insulin in pregnancy. QJM. 2001;94(5):255-60.

6. Mathiesen ER, Kinsley B, Amiel SA, et al. Maternal glycemic control and hypoglycemia in type 1 diabetic pregnancy: a randomized trial of insulin aspart versus human insulin in 322 pregnant women. Diabetes Care. 2007;30(4):771-6.

7. Negrato CA, Montenegro Junior RM, Von Kostrisch $\mathrm{LM}$, et al. Insulin analogues in the treatment of diabetes in pregnancy. Arq Bras Endocrinol Metabol. 2012;56(7):405-14.

8. Nasrallah SN, Reynolds LR. Insulin degludec, the new generation basal insulin or just another basal 
insulin? Clin Med Insights Endocrinol Diabetes. 2012;5:31-7.

9. Russell-Jones D, Gall MA, Niemeyer $M$, et al. Insulin degludec results in lower rates of nocturnal hypoglycaemia and fasting plasma glucose vs. insulin glargine: a meta-analysis of seven clinical trials. Nutr Metab Cardiovasc Dis. 2015;25(10): 898-905.

10. Gough SC, Bhargava A, Jain R, et al. Low-volume insulin degludec 200 units/ml once daily improves glycemic control similarly to insulin glargine with a low risk of hypoglycemia in insulin-naive patients with type 2 diabetes: a 26-week, randomized, controlled, multinational, treat-to-target trial: the BEGIN LOW VOLUME trial. Diabetes Care. 2013;36(9):2536-42.

11. Garber AJ, King AB, Del Prato $S$, et al. Insulin degludec, an ultra longacting basal insulin, versus insulin glargine in basal-bolus treatment with mealtime insulin aspart in type 2 diabetes (BEGIN Basal-Bolus Type 2): a phase 3, randomised, openlabel, treat-to-target non-inferiority trial. Lancet. 2012;379(9825):1498-507.
12. Milluzzo A, Tumminia A, Scalisi NM, et al. Insulin degludec in the first trimester of pregnancy: report of two cases. J Diabetes Investig. 2018;9(3):629-31.

13. Formoso G, Ginestra F, Di Dalmazi G, et al. Empagliflozin, metformin and insulin degludec, during pregnancy: a case report. Acta Diabetol. 2018;55(7): 759-61.

14. European Medicines Agency (EMA). London: Committee for Medicinal Products for Human Use, 2013. http://www.ema.europa.eu/docs/en_GB/docu ment_library/EPAR_-_Product_Information/human/ 002499/WC500139011.pdf. Accessed 17 Jun 2018.

15. Feig DS, Donovan LE, Corcoy R, et al. Continuous glucose monitoring in pregnant women with type 1 diabetes (CONCEPTT): a multicentre international randomised controlled trial. Lancet. 2017; 390(10110):2347-59.

16. Martis R, Brown J, McAra-Couper J, et al. Enablers and barriers for women with gestational diabetes mellitus to achieve optimal glycaemic control-a qualitative study using the theoretical domains framework. BMC Pregnancy Childbirth. 2018;18:91. 